\title{
REFLEXÕES ACERCA DA LITERATURA INFANTIL E FORMAÇÃO DE LEITOR NO CONTEXTO DAS CRECHES MUNICIPAIS DE TOCANTINÓPOLIS: REALIDADES EM DESTAQUE
}

\section{Reflections about children's literature and reader training in the context of child care municipal of Tocantinópolis: realities featured}

\author{
Juliane Gomes de SOUZA* \\ André Teixeira CORDEIRO**
}

\begin{abstract}
RESUMO: O estudo aborda a temática da literatura infantil no espaço da Creche, tendo por lócus de investigação duas instituições do município de Tocantinópolis - TO. Tem por objetivo refletir acerca do uso da literatura infantil no contexto das Creches municipais da referida cidade, as quais serão identificadas por Creche 01 e Creche 02, tecendo uma análise em torno dos aspectos que perpassam sua utilização nessa etapa educativa, acentuando elementos tais como: o uso do acervo literário nessas realidades, a intencionalidade das educadoras no trabalho com a literatura, dentre outros. A metodologia da investigação empreendida baseia-se na observação em sala de aula, aplicação de questionários para as professoras, pesquisa documental e entrevista com gestores das instituições. Assim, verificou-se que o arcabouço literário infantil constitui um referencial amplamente utilizado no exercício constante da ação docente nos espaços institucionais investigados, sendo utilizado com as mais diferentes intenções: estímulo ao desenvolvimento de habilidades, descontração do público infantil, e como elemento essencial no processo de formação do leitor. Nas atividades desenvolvidas nas Creches, é ratificada a importância atribuída pelas professoras à literatura infantil, expressa pela compreensão por parte das educadoras das influências e das contribuições desta na formação da criança.
\end{abstract}

PALAVRAS-CHAVE: Literatura infantil Creche. Criança.

\begin{abstract}
This study covers the thematic of children's literature in the space of a day care center, with the locus of the investigation two institutions in the city of Tocantinópolis - TO. It aims to reflect about the children's literature use no context of municipal day care of that city, as which be identified by day care center 01 and day care center 02, weaving analysis around aspects pervade

its use in this educational stage, accentuating elements such as: the use of the literary collection in these realities, an intentionality of the educators at work with the literature, among others. The undertaken methodology of investigation is based on the observation in the classroom, application of questionnaires to the teachers, documentary research and interviews with administrators of the institutions. The methodology of the research undertaken is based on the observation in the classroom, questionnaires for teachers, documentary research and interviews with managers of the institutions. Thus, it was found that the children's literary framework is a widely used benchmark in the constant exercise of teaching activities in institutional spaces investigated and used with the most different intentions: encouraging the development of skills, relaxation of the child audience, and as an essential element in player of the training process. The activities in day care centers, ratified the importance attached by teachers to children's literature, expressed by the understanding by the educators of the influences and contributions of this in the child's education.
\end{abstract}

KEYWORDS: Children's Literature. Day care Center. Child.

\footnotetext{
*Mestra em Educação pela Universidade Federal do Tocantins - UFT (2017). Professora do Magistério Superior na Universidade Federal do Tocantins UFT/Câmpus de Tocantinópolis - curso de Licenciatura em Educação do Campo com habilitação em Artes e Música.

** Doutor em Literatura Brasileira pela Universidade de São Paulo - USP (2003-2008). Professor adjunto na Universidade Federal do Tocantins.
} 


\section{Introdução}

A literatura infantil, cuja especificação designa seu público alvo, constitui uma ramificação da literatura, a qual teve, em seu surgimento, forças sociais que delinearam sua configuração. Assim, "com base em características muito peculiares, tem-se designado como literatura infantil um dos aspectos da literatura dentre as várias modalidades artísticas." (SOSA, 1985, p. 14), cuja adjetivação tem por objetivo a aproximação cada vez maior com o seu público destinatário.

Desse modo, a literatura infantil surge no século XVIII em decorrência de uma configuração social marcada pela ascendência da burguesia. Essa classe da sociedade passa a reconhecer e a definir um novo status para a criança pequena, reconhecendo essa fase da vida como infância - conceito, até então, inexistente, em virtude da não separação entre mundo adulto e infantil no modelo de família feudal.

Diante disso, essa conjuntura exigiu a criação de instituições que transmitissem e firmassem os novos valores sociais. Dentre essas, a escola foi instituída como lócus privilegiado para a formação dos futuros cidadãos burgueses. Nesse cenário, a escola buscou criar e fomentar ferramentas que contemplassem sua missão ideológica, entre elas a literatura.

Pelo exposto, evidencia-se o objeto da investigação proposta, a literatura infantil, a qual constituiu o cerne da presente pesquisa, delineada e efetivada no espaço da Creche. Esta foi situada como instituição que, assim como a produção literária destinada à infância, foi constituída pela necessidade de atenção à criança pequena. Destarte, o surgimento da Creche teve também por contexto as mudanças oriundas da sociedade, principalmente, no que se refere aos aspectos econômicos.

Nesse escopo, a sociedade capitalista ganha força com o processo de industrialização, o qual firma novas possibilidades, dentre elas, a inserção da mulher no mercado produtivo. Essa variante modifica o papel desenvolvido pela mulher, cujas atribuições consolidavam-se na realização de atividades domésticas. Nessa conjuntura, a criança pequena precisava ser acolhida em um espaço externo ao familiar, destinado à guarda e à assistência, enquanto as mães serviam ao interesse do capital. É nessa fase, desencadeada no continente europeu, que são postuladas as primeiras instituições de atendimento à infância.

Considerando esse cenário e o conjunto de informações apresentadas, foram levantados alguns questionamentos que balizaram a pesquisa, tendo por centralidade a literatura infantil no espaço de duas Creches municipais de Tocantinópolis, os quais versaram 
sobre: o uso do acervo literário nessas realidades, a intencionalidade das educadoras no trabalho com a literatura, bem como as metodologias por elas utilizadas.

A justificativa da abordagem dessa temática insere-se na perspectiva de que, na atualidade, os documentos legais, como o Referencial Curricular Nacional para a Educação Infantil (RCNEI), ratificam a importância e a necessidade da inserção da literatura na educação infantil, como forma de contribuir para o desenvolvimento de habilidades.

Além disso, muito se tem falado na formação da criança em um viés de letramento, pautado nos usos sociais da leitura e da escrita. Este fenômeno, letramento, é entendido como "[...] o estado ou condição de quem interage com diferentes portadores de leitura e de escrita, com diferentes gêneros e tipos de leitura e de escrita, com as diferentes funções que a leitura e a escrita desempenham na nossa vida." (SOARES, 2006, p. 44). Desse modo, o contato intenso com diferentes fontes de informações auxilia e contribui para o exercício, desde a primeira infância, da leitura e da escrita como práticas sociais. Assim, torna-se contundente investigar como a literatura, nessa etapa educativa, tem contribuído para esse processo.

Nesse sentido, o objetivo delineado para a pesquisa encaminhada consistiu em: refletir acerca do uso da literatura infantil no contexto das Creches municipais de Tocantinópolis TO, as quais serão identificadas por Creche 01 e Creche 02, tecendo uma análise em torno dos aspectos que perpassam sua utilização nessa etapa educativa.

Desse modo, procurando sanar as indagações suscitadas, a metodologia adotada incidiu em uma abordagem quantitativa e qualitativa de cunho exploratório, tendo em vista que, com esse procedimento,

[...] o pesquisador faz a convergência de dados quantitativos e qualitativos a fim de obter uma análise ampla do problema de pesquisa. Nesse projeto, o investigador coleta as duas formas de dados ao mesmo tempo durante o estudo e depois integra as informações na interpretação dos resultados gerais (CRESWELL, 2007, p. 33).

O uso de tal abordagem justifica-se pela possibilidade que apresenta da integração de diferentes tipos de dados, o que contribui para ampliar a interpretação e o entendimento acerca de um determinado assunto.

Nessa perspectiva, foi empreendida a utilização de questionários com professoras das duas instituições assinaladas, atingindo o total de 13 educadoras que se dispuseram a contribuir para a pesquisa, dentre as quais 07 eram atuantes da Creche 01 e 06 professoras da 
Creche 02. O referido instrumento de coleta de dados continha perguntas que abordavam o trabalho desenvolvido pelas docentes no contexto da educação infantil, buscando inferir a utilização da literatura infantil em suas práticas pedagógicas. As educadoras serão identificadas por números, como requisito apontado no decorrer da pesquisa.

Com o intuito de contextualizar os espaços institucionais, recorreu-se à análise documental, efetivada por meio do estudo do Projeto Político-Pedagógico das Creches. Nesse escopo, buscou-se verificar aspectos históricos, criação, origem, bem como dados referentes a projetos desenvolvidos no lócus das instituições. O objetivo desse levantamento consistiu em extrair informações preliminares que fornecessem base para o desenvolvimento da pesquisa.

Também foi realizada entrevista estruturada com os gestores das Creches, utilizando, para tanto, um quadro (formulário), abordando os seguintes aspectos: ano de fundação das instituições; quantitativo de crianças matriculadas e turmas em funcionamento; número de funcionários e respectiva formação; existência e quantitativo de livros de literatura infantil; dentre outros elementos que possibilitaram visualizar as unidades educativas em sua configuração atual.

Realizou-se, ainda, a observação, no decorrer de uma semana, em cada local, cujo objetivo assentou-se em verificar se o trabalho desenvolvido pelas docentes, em seu fazer pedagógico, contemplava a literatura infantil. Com isso, a centralidade desses momentos voltou-se para o trabalho didático desenvolvido pelas professoras, nas atividades realizadas em sala, nos espaços destinados à leitura e nos projetos em andamento nos períodos da observação, que foram: na Creche 01, no período de 20 a 24 de outubro de 2014, na sala do Maternal II; e na Creche 02, entre os dias 28 e 31 de outubro de 2014, também no Maternal.

Com essa abordagem, a temática literatura infantil no contexto da Creche é apresentada, tendo por base uma pesquisa no campo prático, embasada por referencial teórico referente à área investigada.

\section{A literatura infantil no espaço das Creches: suas relações no contexto da pesquisa}

A partir da metodologia anteriormente apresentada, foi realizada a pesquisa no campo prático, tendo por cenário duas instituições de educação infantil do município de Tocantinópolis. Nesse sentido, é válido ressaltar que a abordagem adotada se encaminha para uma reflexão conjuntural dos dados obtidos, não tendo o objetivo de comparar e/ou segmentar 
a análise por instituição, mas sim fazer um caminho reflexivo que contemple o entendimento da relação literatura e Creche em seus diferentes aspectos nos contextos pesquisados, atentando-se para um viés analítico dos dados, referendado em uma perspectiva global.

A partir dessa conjectura, assinala-se que, segundo as Diretrizes Curriculares Nacionais para a Educação Infantil, a partir dos eixos curriculares interação e brincadeira, é importante que as atividades na prática pedagógica da educação infantil: "possibilitem às crianças experiências de narrativas, de apreciação e interação com a linguagem oral e escrita, e convívio com diferentes suportes e gêneros textuais orais e escritos." (BRASIL, 2010, p. 23). Esse marco legal ratifica a importância e a necessidade, como aspecto metodológico que contribui para o desenvolvimento das habilidades infantis, da inserção contínua e ativa da prática de leitura na ação pedagógica no espaço da educação infantil. Portanto, é indispensável à realização de atividades de letramento.

Sendo assim, o primeiro elemento que se destacou no questionário aplicado às professoras é que $100 \%$ das profissionais atuantes no espaço de sala nessas instituições são mulheres, uma validação que corrobora com o processo histórico da feminização do trabalho docente. A esse respeito, Pinto (2011, p. 175, grifo nosso) assinala:

A profissão docente apresenta algumas marcas históricas: desvalorização e proletarização do professor, exercício eminentemente realizado pelo gênero feminino, o caráter de "sagrado", originário, talvez, de suas origens eclesiásticas. Essas marcas constituem a identidade da profissão e contribuem para mantê-la como um fazer de baixa aspiração profissional, a ser desenvolvida por pessoas generosas que, portanto, mesmo que reconhecidamente merecedoras, contentam-se com baixos salários e condições de trabalhos modestos.

Essa tendência histórica tem caracterizado, inclusive, a predominância do gênero feminino nos cursos voltados para a formação de professores, sendo essa prevalência corroborada pela atuação de profissionais - a maioria do gênero feminino - no âmbito da educação infantil.

Outro elemento que merece destaque nesse contexto de análise refere-se ao tempo de atuação das educadoras no contexto da educação infantil. De acordo com os percentuais levantados, verifica-se que a maioria das educadoras, cerca de 53,8\%, atuam de 08 a 16 anos na educação infantil, o que representa uma considerável experiência profissional. Essa constatação leva a entender que as ações da prática pedagógica desse grupo docente podem ser sólidas nesse nível educacional. 
A constatação acima ratifica outra informação, a de que as docentes entrevistadas afirmam, de maneira unânime, que fazem uso do arcabouço literário infantil de maneira ativa no exercício constante de sua ação, o que, pelo exposto acima, é duradouro nessa etapa educativa. Essa validação revela-se importante para o processo de formação da criança, pois o contato frequente com a literatura possibilita ao infante inúmeras vantagens, dentre elas a aproximação com a linguagem escrita e oral, essa sendo trabalhada, segundo o Referencial Curricular Nacional para a Educação Infantil (v. 03), como

[...] um dos eixos básicos na educação infantil, dada sua importância para a formação do sujeito, para a interação com as outras pessoas, na orientação das ações das crianças, na construção de muitos conhecimentos e no desenvolvimento do pensamento (BRASIL, 1998, p. 114).

Além disso, a literatura, de modo frequente no ambiente da Creche, desperta a atenção, o gosto pelo hábito da leitura, o que auxilia na formação do leitor - objetivo explícito na proposição dessa etapa educativa. Por isso, afirma-se:

[...] lendo todos os dias você garante que a leitura se torne parte integrante da rotina [...]. É este contato frequente, diário e constante que permite que os alunos construam uma crescente autonomia para ler, familiarizem-se com a leitura, conheçam uma diversidade de história e autores, entre outros ganhos (SÃO PAULO, 2010, p. 25).

Nesse viés, pautado na prerrogativa de que a educação infantil deve favorecer e estimular a criança no desenvolvimento de diversas habilidades (físicas, cognitivas, sociais, de linguagem, dentre outras), fica explícito que as atividades desse nível deverão ser encaminhadas para o processo de letramento do seu público.

Dessa maneira, um elemento relevante é a compreensão, por parte das educadoras, da influência e das contribuições advindas pelo uso da literatura. A esse respeito, quando as professoras foram indagadas se já tinham desenvolvido algum projeto utilizando a literatura infantil, o posicionamento de uma professora assinala o reconhecimento dessas influências: “[...] na educação infantil não se trabalha sem a leitura infantil, pois é momento de prazer e desenvoltura." (Professora 04 - Creche 01). Esse argumento explicita a relevância atribuída à utilização da literatura, tanto no que concerne ao nível educacional, quanto à presença desta na prática da profissional, visto que a afirmação, em sentido categórico, assegura o posicionamento dela, "na educação infantil não se trabalha sem a leitura". 
Assim, dentre os gêneros e suportes textuais elencados no questionário, os quais sejam: narrativas (histórias), poesias, piadas, cantigas de roda, parlendas, trava-línguas, em jornais, livros e revistas, constatou-se que os mais utilizados são, respectivamente, as cantigas de roda e as narrativas (histórias).

Com isso, o que se verifica, tanto pela mensuração dos questionários como pela observação empreendida nas salas, é que as canções infantis, desde as mais clássicas (cantigas de roda) como as contemporâneas, perpassam todo o cotidiano da prática pedagógica no espaço de sala da Creche. Nesse sentido, é válido acentuar que

O estímulo do sentido da audição com mensagens sonoras que ativem as áreas do cérebro responsáveis pela aprendizagem de novos conteúdos, informações e habilidades motoras mais complexas são um excelente recurso que o educador poderá utilizar (OLIVEIRA, 2013, p. 88).

Assim, ressalta-se que a música compartilhada por um grupo de crianças em um momento de interação possibilita ao infante a assimilação de palavras, a descoberta de sons e entonação, bem como estimula à movimentação corporal, despertando habilidades como equilíbrio e coordenação.

No tocante às narrativas (histórias), estas, inicialmente originárias dos relatos orais, também são um gênero fortemente presente no trabalho com a literatura desenvolvido nas duas instituições. Quando as professoras foram questionadas acerca do último título trabalhado em sala, os mais citados consistiam-se de histórias clássicas, oriundas de influências do contexto europeu, as quais eram: "Chapeuzinho vermelho", "Os três porquinhos", "João e o seu pé de feijão", "A galinha e a raposa", "Cachinhos dourados e os três ursos". E, como exceção, "Sítio do Picapau Amarelo", de Monteiro Lobato.

O uso predominante dessas narrativas, consideradas como clássicas, advém da forte influência das adaptações de histórias infantis europeias e de sua intensa inserção no cenário brasileiro. Portanto, algumas das histórias fantásticas consolidam-se como obras centrais ao se falar em contação de histórias infantis nas realidades em foco.

Contudo, é salutar atentar-se para o exposto por Oliveira (2013, p. 73):

O contador de histórias deve levar em conta a faixa etária dos ouvintes. Os interesses das crianças pequenas se voltam para histórias repetitivas ou acumulativas [...]. Elas gostam de livros ilustrados, fábulas rimadas, de versos infantis, de contos de fadas ou livros só de imagens, sem palavras. 
Essas características - faixa etária, público, forma de abordagem - são fundamentais para o bom desempenho da atividade literária, às quais o contador de histórias deverá atentarse.

Em outro ponto de análise, constatou-se o comprovado interesse pelo livro por parte do público das crianças pequenas, fato este corroborado por meio de uma ação acompanhada no desenvolvimento da pesquisa. Durante a observação em sala, um grupo de crianças, voluntariamente, teve acesso a dois livros de histórias infantis, e o contato com estes revelou um momento de grande concentração das crianças envolvidas. Visivelmente, percebeu-se o deslumbramento no folhear, apreciar as imagens e em apresentar a descoberta (os livros) aos colegas no entorno. Caracterizou-se como momento de encantamento, que culminou na contação de histórias infantis pela professora, período que tornou perceptível, no público presente, o desejo de ouvir e de participar do enredo narrado. Diante disso, é válido assinalar que,

Se observarmos atentamente, veremos que é destas práticas, de ouvir e contar histórias, que surge a nossa relação com a leitura e a literatura. Portanto, quanto mais acentuarmos no dia-a-dia da Escola Infantil estes momentos, mais estaremos contribuindo para formar crianças que gostem de ler e vejam no livro e na literatura uma fonte de prazer e divertimento (KAERCHER, 2001, p. 82).

Com base nessa acepção, vislumbra-se que essa atenção despertada pelo livro, pela literatura, verificada no contexto das ações acompanhadas, pode estar ligada ao trabalho pedagógico das educadoras, que buscam inserir em suas práticas a literatura como componente.

Ademais, diante da constatação da utilização da literatura infantil no ambiente da Creche, foi realizado um levantamento acerca das metodologias utilizadas pelas professoras no uso do acervo literário. Assim, identificamos diversas, as quais são: uso de fantoche; o cantar com a turma; contação de histórias; roda de conversa; dramatização; uso de gravuras; encenação de peças teatrais; desenho; uso de cartazes; apresentação de vídeos. Essa diversidade metodológica é importante devido à especificidade do público, tendo em vista que a maneira como a literatura é abordada, planejada, encaminhada pode ou não agradar, chamar a atenção, influenciar.

Vindo ao encontro dessa constatação, a importância de uma metodologia adequada efetivou-se no campo prático, pois durante a observação foi vivenciada uma atividade com o uso da literatura infantil envolvendo narrativas (histórias), em que ficou explícita a 
inexistência de uma preparação e de um planejamento adequado. A atividade consolidou-se de forma desinteressada por parte dos educandos, sendo que a responsável pela leitura (monitora) declarou abertamente não ter conhecimento prévio da história narrada. Tal comportamento refletiu, diretamente, na falta de atenção das crianças, que demonstraram, mesmo, total falta de atenção, por uma leitura descompromissada e aleatória.

Assim, é fundamental que essa atividade seja encaminhada de maneira atenta, visto que

[...] quando se vai ler uma história - seja qual for - para a criança, não se pode fazer isso de qualquer jeito [...]. Por isso, ler o livro antes, bem lido, sentir como nos pega, nos emociona ou nos irrita... Assim quando chegar o momento de narrar a história, que se passe a emoção verdadeira, aquela que vem lá de dentro, lá do fundinho, e que por isso chega no ouvinte (ABRAMOVICH,1997, p. 19-20).

Concorda-se com a autora, uma vez que o trabalho desenvolvido no espaço da Creche tem por centralidade um público peculiar, que necessita de atividades motivadoras e interessantes para o despertar da atenção.

No que concerne à importância do emprego da literatura infantil na Creche, 100\% das professoras declararam fazer uso desse elemento, devido a suas contribuições para o público infantil. Sendo assim, de forma geral, as justificativas para a inserção da literatura em suas práticas pedagógicas giram em torno de aspectos que são ratificados/assinalados de acordo com os seguintes argumentos:

"Importante porque ajuda no desenvolvimento das crianças em relação à linguagem oral e escrita, socialização e interação, nas coordenações motora e grossa, na percepção, atenção e raciocínio.” (Professora 12 - Creche 02).

"Porque ajuda os alunos a desenvolver a imaginação, atenção, interesse pela leitura, pois os mesmos observam, manuseiam livros e fazem perguntas." (Professora 13 - Creche 02).

"O trabalho com a literatura infantil na creche é muito importante, pois através dela as crianças desenvolvem a imaginação, coordenação e outras habilidades." (Professora 10 - Creche 02).

"Pois é uma prática lúdica, que influencia os alunos a desenvolver o gosto e o hábito pela leitura." (Professora 03 - Creche 01).

Esses argumentos expressam a literatura infantil como fator importante e essencial ao trabalho na educação infantil, os quais apontam a utilização/direcionamento do acervo literário para a satisfação de diversos interesses, desde o incentivo ao hábito de ler até o 
desenvolvimento de habilidades físicas e cognitivas. A percepção desse potencial da literatura faz com que se justifique o fato de todas as educadoras entrevistadas atestarem a utilização contínua desse elemento em suas práticas pedagógicas.

Contudo, a partir da mensuração, o que se observa é que o argumento mais utilizado refere-se à importância da literatura infantil como maneira de despertar na criança o gosto pela leitura e a consequente influência na formação de leitores, como acentua uma professora: “[...] é de fundamental importância, pois desde cedo as crianças devem ser estimuladas a ler, para se tornarem boas leitoras e aprendam a gostar e ter prazer em ler" (Professora 01 Creche 01). Desse modo, podemos perceber que o contato com a literatura, desde a primeira infância, é fundamental para o despertar de leitores. A educação infantil, assim, é a base para a formação de um indivíduo com hábitos ativos de leitura e escrita.

Essa intencionalidade coincide com uma preocupação recente, a de formar bons leitores na sociedade atual que se firma, cada vez mais, como digital, com a veiculação de informações rápidas. Assim, segundo Abramovich (1997, p. 16),

[...] é importante para a formação de qualquer criança ouvir muitas, muitas histórias... Escutá-las é o início da aprendizagem para ser um bom leitor, e ser leitor é ter um caminho absolutamente infinito de descoberta e de compreensão do mundo.

Por conseguinte, foi assinalado, como expresso anteriormente, que de maneira unânime as professoras declararam possuir o hábito de utilizar a literatura infantil no espaço de sala. Todavia, no que se refere à frequência habitual, há uma oscilação, que se configura de acordo com o gráfico 01:

\section{Gráfico 01: Frequência no uso da Literatura Infantil. ${ }^{\dagger}$}

\footnotetext{
${ }^{\dagger}$ O gráfico integra informações das duas realidades investigadas, cujo objetivo é a visualização do uso da literatura infantil nessa etapa educativa.
} 


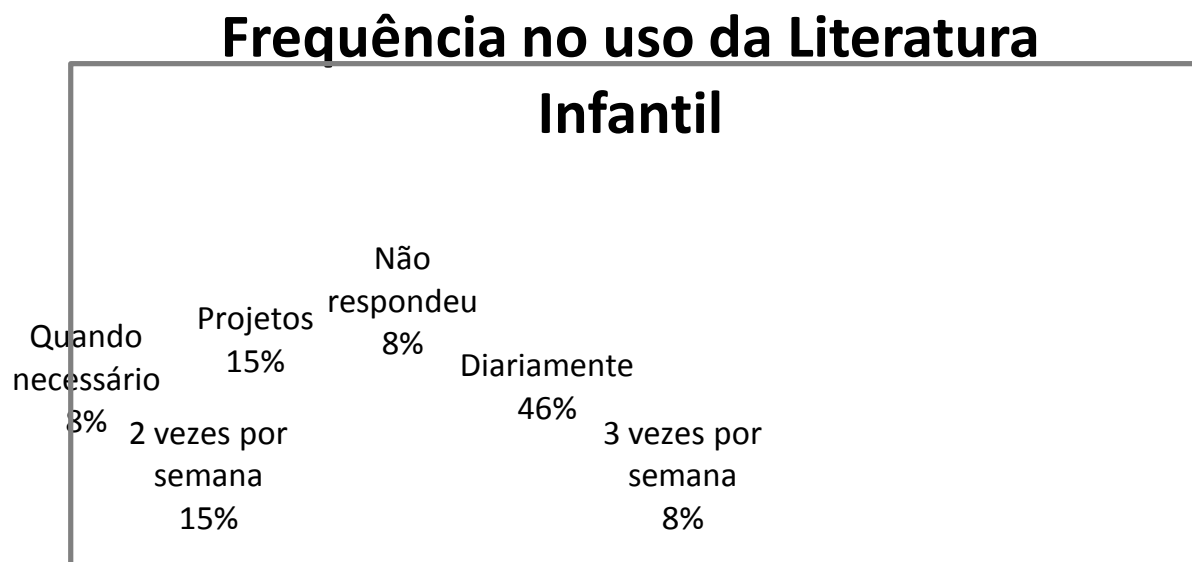

Fonte: Pesquisa 2014

É perceptível que a inserção da literatura nas realidades investigadas segue um fluxo dinâmico, sendo que, no panorama exposto, dois aspectos chamam atenção. O primeiro é o fato de o uso literário ser associado à necessidade de algum objetivo (quando necessário: 8\%). Essa afirmativa leva a constatar que existe uma intencionalidade, um objetivo, que justifica o uso esporádico da literatura infantil na prática pedagógica. Todavia, o hábito cotidiano, assinalado no gráfico por $46 \%$, acentua a presença da literatura infantil de maneira recorrente no espaço da Creche.

Contudo, acredita-se que esse quantitativo possa ser ampliado, uma vez que a educação infantil configura-se como espaço privilegiado para despertar o gosto pela leitura, pois é o momento inicial em que a criança começa a formular suas primeiras impressões formais no que concerne aos hábitos da leitura e da escrita.

O segundo aspecto que se destaca é o desenvolvimento de projetos, que são concretizados de forma coletiva por toda a equipe pedagógica, caracterizando um processo metodológico presente nas duas instituições. Assim sendo, os projetos direcionam as atividades a serem realizadas, guiadas por objetivos, de acordo com a temática abordada.

[...] o trabalho por projetos permite, realmente, que todos os integrantes... orientem suas ações para o cumprimento de uma finalidade compartilhada [...] favorece o desenvolvimento de estratégias por parte dos alunos e abre as portas da classe para uma nova relação entre o tempo e o saber (LERNER, 2002, p. 22). 
Nas instituições analisadas, a literatura compõe projetos que, embora consolidados pela coletividade, as professoras desenvolvem-nos em ações individuais com suas turmas. E a culminância desses dá-se, frequentemente, por meio de mostras literárias.

Quanto ao interesse das crianças pela leitura, todas as professoras pesquisadas afirmam que há uma atenção especial no momento da leitura, inclusive uma educadora descreve: "O silêncio é absoluto" (Professora 04 - Creche 01). Logo, constata-se que a literatura exerce uma influência benéfica na criança, constituindo-se como atrativo ao universo infantil, pois, dentre outros elementos, insere o infante em um "mundo" guiado pela fantasia, imaginação. Nesse mundo, ao mesmo tempo em que aborda um contexto fictício permeado pelo faz de conta, a criança depara-se com situações reais do seu dia a dia, como angústias, conflitos, emoções, que vão influenciá-la a resolver suas próprias questões. Nessa perspectiva,

A criança, o jovem e até o adulto apreciam o maravilhoso, o belo, o fantástico, o verdadeiro, gostam da aventura, do desafio, identificam-se com as personagens, com as emoções que eles transmitem, trabalham suas emoções básicas como o medo, a alegria, o afeto, a raiva, a tristeza, a dor, a dúvida [...] (OLIVEIRA, 2013, p. 85).

Em outro ponto de análise, verificou-se a existência ou não de espaços dentro das instituições voltadas para acomodação de acervo literário, bem como local de visita e leitura. Assim, no tocante a esses espaços, existe uma diferença entre as duas realidades em foco, pois, na Creche 01, existe uma sala de leitura, com acervo bibliográfico de 250 livros em média, segundo o gestor, distribuído pelo Ministério da Educação (MEC) via Secretaria Municipal de Educação.

Na Creche 02, não há um local ${ }^{\ddagger}$ específico e coletivo para a prática da leitura (como biblioteca ou sala de leitura), sendo que, segundo a gestora, a unidade educacional conta com uma média de 100 livros de literatura infantil, também disponibilizados pelo governo federal. Todavia, $61,5 \%$ das professoras afirmaram que no contexto de sala há um espaço destinado à leitura, em que o Cantinho da Leitura foi o mais assinalado.

Refletir acerca desses ambientes de fomento à leitura é fundamental, haja vista que esses se convertem em locais onde a criança vivencia intensamente o contato com os

\footnotetext{
* Atualmente (2016), nas novas instalações (prédio) da Creche 02, existe um espaço dedicado à leitura. A pesquisa foi realizada no antigo prédio, no ano de 2014.
} 
diferentes gêneros textuais nos seus variados suportes. Dessa forma, a relação, na educação infantil, com uma variedade de textos possibilita à criança a ampliação e a percepção de que, socialmente, a leitura e a escrita estão expressas nos diferentes suportes do cotidiano.

$\mathrm{Na}$ investigação encaminhada, foi visualizado que existem intencionalidades, guiadas por objetivos claros, das educadoras no trato com a literatura infantil, tendo em vista que as docentes confirmaram o desenvolvimento de algum tipo de atividade após a abordagem dos diversos gêneros. De acordo com essa validação, realizou-se o levantamento das atividades, que, pelas respostas assinaladas, distribuem-se em: realização de rodas de conversa; teatro; desenho ou pintura.

É válido ressaltar que, dentre estas, a roda de conversa é a ação vivenciada por todas as professoras. A intencionalidade com o uso dessa metodologia é o estímulo à expressão oral e consiste em indagações direcionadas às crianças. Os alunos recontam a obra narrada, identificam personagens e realizam interferências com frequência.

Outra intencionalidade expressa é o estímulo à interpretação e à representação dos gêneros literários abordados em sala. Sendo assim, foi percebido que as profissionais, para cumprirem tais finalidades, utilizam como estratégia metodológica a pintura e/ou desenhos. Nessa ação, solicitam que o público infantil represente os elementos presentes nas obras literárias. Como exemplo, foi identificado e realizou-se o acompanhamento do Projeto Música, desenvolvido na instituição Creche 01.

Ainda no âmbito da intencionalidade no uso da literatura infantil, a proposição quanto ao desenvolvimento de habilidades também se converte em um objetivo das educadoras. Assim, por meio das características literárias, buscam despertar e estimular o desenvolvimento de aspectos físicos e cognitivos.

No entanto, é importante frisar que a literatura infantil é formativa por suas próprias características, como coloca Amarilha (1993), pois a criança internaliza elementos retratados pelo universo literário sem a necessidade, para tanto, de um atrelamento/direcionamento pedagógico. Em muitos casos, didatiza-se excessivamente a literatura.

\section{Considerações Finais}

Em uma perspectiva analítica, constata-se que ambas, literatura infantil e Creche, foram adotadas como medidas requeridas e voltadas a atender anseios do contexto sócio- 
histórico. De acordo com essa acepção, originariamente, não se constituíam em um direito da criança, inexistindo até mesmo a compreensão de este Ser como detentor de direitos.

Assim, tendo por base o exposto neste trabalho, evidencia-se que a literatura infantil é um elemento presente no espaço educacional da Creche 01 e da Creche 02. Nestas, o trabalho com a modalidade literária em questão concretiza-se, rotineiramente, na prática pedagógica das professoras. Este abrange tanto o trabalho individual das educadoras, como engloba uma esfera mais ampla no âmbito da instituição, por meio de projetos temáticos, assinalados no Projeto Político-Pedagógico (PPP) e efetivados no decorrer do ano letivo.

Além disso, lançando mão de um conjunto de gêneros orais e escritos (músicas, narrativas, contos, poesias, fábulas), é perceptível, também, a intenção de dinamizar as atividades em sala e de descontrair o público infantil. Ademais, constatou-se que os gêneros mais utilizados são as cantigas de roda e as narrativas.

Destarte, para o desempenho das atividades em que a literatura constitui-se como integrante, o uso de metodologias é amplo, e contempla: desde o manuseio com diferentes gêneros, pelas crianças; a encenação verbal, apreciada coletivamente; até a leitura, realizada pelo professor, de diferentes livros infantis, geralmente bastante ilustrados e coloridos.

Entende-se, portanto, que a literatura infantil configura-se como ferramenta metodológica nesses espaços educacionais. Está direcionada a atender objetivos claros, manifestados nas práticas pedagógicas das educadoras dessa etapa educativa. Desse modo, em um novo cenário social, em que a criança é vista como sujeito de direitos, a literatura mais uma vez é solicitada em uma perspectiva formativa.

Assim, reafirma-se a importância da literatura infantil no contexto da Creche. Suas contribuições implicam em diversos benefícios (desenvolvimento da imaginação, senso crítico, interpretação de textos, desenvolvimento da linguagem oral e coordenação motora, dentre outros), que tendem a contribuir para a criança em fase de desenvolvimento.

Todavia, embora verificadas as possibilidades e potencialidades da literatura infantil nas instituições pesquisadas, alguns pontos merecem ser elucidados, como forma de contribuir para uma reflexão acerca de elementos que precisam ser repensados. Um dado equivocado percebido é que, em alguns momentos, a literatura infantil era vista como simples atividade substitutiva, esporadicamente, em decorrência da ausência de um planejamento. Esse fato fazia com que a leitura de um livro fosse realizada sem uma preparação, o que a 
transformava em uma verdadeira leitura aleatória, linear e sem nenhum atrativo para o público infantil, verificando-se a dispersão e a falta de atenção pelo modo como era apresentada.

Outro fator que merece destaque volta-se para a didatização da literatura infantil, pois foi observado que, não raro, houve ocasiões, nos dois contextos investigados, em que a literatura era utilizada com um viés de alfabetização - objetivo este que não é próprio da educação infantil, e ainda pode converter o objeto literário em simples instrumento didático.

\section{Referências}

ABRAMOVICH, Fanny. Literatura infantil: gostosuras e bobices. 5. ed. São Paulo: Scipione, 1997.

AMARILHA, Marly. Estão mortas as fadas? Literatura infantil e prática pedagógica. Petrópolis- RJ: Vozes, 1993.

BRASIL. Diretrizes curriculares nacionais para a educação infantil. Ministério da Educação e do Desporto, Secretaria de Educação Fundamental. Brasília: MEC/SEF, 2010.

BRASIL. Referencial curricular nacional para a educação infantil. Ministério da Educação e do Desporto, Secretaria de Educação Fundamental. Brasília: MEC/SEF, 1998.

CRESWELL, John W. Projeto de pesquisa: métodos qualitativo, quantitativo e misto. Tradução Luciana de Oliveira da Rocha. 2. ed. Porto Alegre: Artmed, 2007.

KAERCHER, Gládis E. E por falar em literatura... In: CRAIDY, Carmem Maria; KAERCHER, Gládis Elise P. da Silva (Org.). Educação infantil: pra que te quero? Porto Alegre: Artmed, 2001.

LERNER, Delia. Ler e escrever na escola: o real, o possível e o necessário. Tradução Ernani Rosa. Porto Alegre: Artmed, 2002.

OLIVEIRA, Gladis Pedersen de. A literatura e a magia da arte de contar histórias. Porto Alegre: Olsen, 2013.

PINTO, Ivone Maciel. Docência inovadora na universidade. 2011. 365 fls. Tese de Doutorado em Educação. Universidade Federal de Goiás, Goiânia, 2011.

SÃO PAULO/Prefeitura Municipal. Guia pedagógico. Ler e escrever. Parte I, 2010.

SOARES, Magda. Letramento: um tema em três gêneros. Belo Horizonte: Autêntica, 2006.

SOSA, Jesualdo. A literatura infantil. Tradução James Amado. São Paulo: Cultrix; Universidade de São Paulo, 1985. 